interaction between noise pollution and wildlife species as well as outlining strategies for the reduction or even prevention of noise impacts [12]. In this case, modeling offers a powerful means to address this objective [12, 13]. Spatial sound propagation modeling can provide useful insights into better understanding and prediction of the noise pollution effects on species and ecosystems [11]. Various environmental and landscape factors contribute to noise propagation in natural ecosystems, among which are: topographical features, weather conditions, land-use land-cover types, and the attributes of the propagating source(s) $[11,12]$. This multitude of contributing factors indicates that noise propagation modeling is a complex field and requires specific tools [14]. The SPreAD-GIS, developed by Reed et al. (2012), is a robust tool for ambient sound propagation modeling. This tool has the advantage of being freely available and easy-to-implement as well as being specifically designed to model sound propagation in natural environments relying on multiple contributing factors [11]. As an ArcGIS toolbox, SPreAD-GIS has shown to be an adequate approach to efficiently modeling noise propagation from oil and gas compressors [14] and selecting locations for assessing the effect of highway noise on bird species [15].

As one of the most important infrastructures for transporting persons and goods, roads are a major source of noise pollution in natural areas [8-10]. Worldwide projections suggest that the total road length will grow by $60 \%$ between 2010 and 2050, of which around $90 \%$ will take place in developing countries $[16,17]$. Roads penetrating into protected areas are a major proximate driver for structural habitat loss and fragmentation [10, 18]. The severity of these effects becomes even greater when focusing on road-induced noise pollution instead of land-take (i.e., functional habitat loss and fragmentation) $[10,17,19,20]$. Road construction within Iranian protected areas has led to serious concerns about endangering integrity and resilience of natural ecosystems. Mouteh Wildlife Refuge is well known in Iran as a road-affected protected area. Although Mouteh provides highly suitable habitats for Persian gazelle (Gazella subgutturosa subgutturosa), there is a west-east four-lane highway that divides the area into two completely disconnected parts, disrupting Persian gazelles from proper movement and utilization of habitat resources. Therefore, this study aimed to: (1) model propagation of noise from the constant stream of cars during cold and warm seasons, (2) identify and prioritize potential suitable habitats for Persian gazelle populations in the wildlife refuge, and (3) determine to which extent and degree Persian gazelle habitats are impaired by noise pollution.

\section{Study area and species}

The Persian gazelle (Gazella subgutturosa subgutturosa) is a subspecies of the goitered gazelle (Gazella subgutturosa) that ranges from eastern Turkey to Iran, Pakistan, Turkmenistan, and east central Asia [21]. Despite having such a wide geographical distribution, mostly illegal hunting and habitat loss have severely reduced their abundance throughout the species' range [22, 23]. Hence, the species' status in the IUCN Red List was recently re-evaluated and changed from Near Threatened to Vulnerable. Goitered gazelles communicate using a series of deep grunts, hissing, mooing, and wheezing. They often make a nasal hiss as an alarm before running. Females make hoarse, lowpitched sounds to call their calves while a calf responds by making a low-pitched "moo." During the breeding season, males make a low wheezing sound, which may be heard from 100 to $150 \mathrm{~m}$ away [22]. Hence, noise pollution can have detrimental impacts on the communication of this species.

Mouteh Wildlife Refuge is a prime site for this species in Iran. It is renowned for hosting one of the largest and thus healthiest populations of Persian gazelle in Iran. Mouteh is situated on the territory of two provinces, Isfahan and Markazi. With an approximate extent of 205,000 ha, it ranks as one of the largest protected areas in the central plateau of Iran (Fig. 1). The mean annual temperature and precipitation of the area are $13.4^{\circ} \mathrm{C}$ and $208 \mathrm{~mm}$, respectively. This area is home to 478 plant, 88 bird, 27 mammal, 26 reptile, and 17 amphibian species. Despite being endowed with a rich biodiversity, Mouteh has been faced with a number of anthropogenic threats. One of the biggest threats comes from a four-lane highway running about $44 \mathrm{~km}$ through the central plain of the wildlife refuge to connect Golpaygan City with the Mouteh Crossroad (Fig. 1).

\section{Methodology}

The SPreAD-GIS model was employed in this study to model road traffic noise propagation above background sound levels. This model is fed by information about the location and characteristics of the sound source(s) as well as their peripheral physical conditions [11]. The steps undertaken to calibrate this model are as follows:

\subsection{The characteristics of the sound sources}

SPreAD-GIS is a static model that works with point sources [11] while vehicles are mobile sources, emitting noise along the entire length of a road. To cope with this 


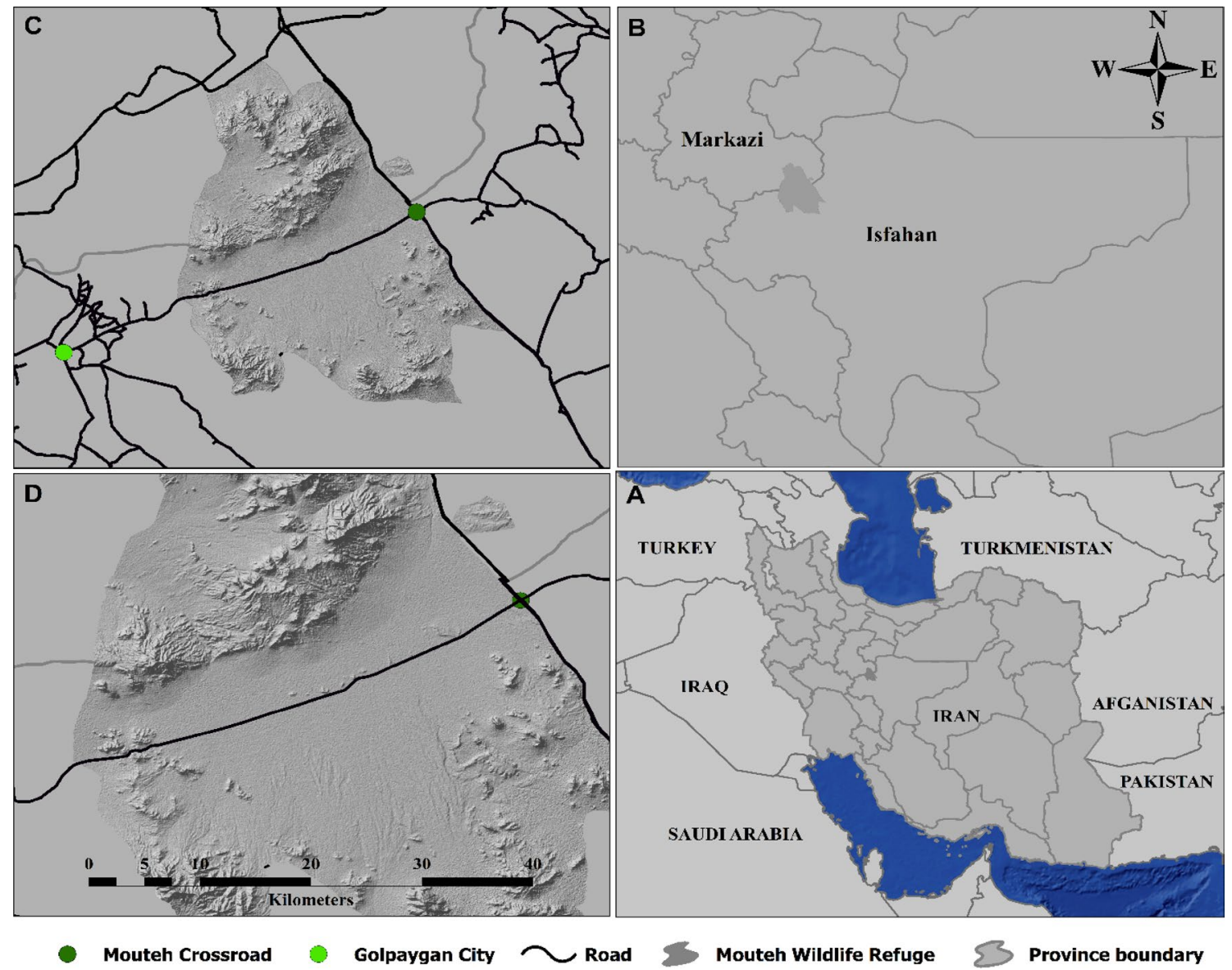

Fig. 1 Geographic location of a Iran, $\mathbf{b}$ Mouteh wildlife refuge, $\mathbf{c}$ the study road, and $\mathbf{d}$ topographic conditions of Mouteh wildlife refuge

inconsistency, the average number, location, and types of vehicles passing through the study road were determined by visual interpretation of Google Earth images and analyzing a 6-year traffic dataset (2010-2015) obtained from the Iranian Road Maintenance and Transportation Organization (Table 1; Fig. 2). Because the Google Earth images are related to 9 a.m-12 p.m., we verified the results of Google Earth images visual interpretation with traffic and vehicle type recorded in the same period by the Iranian Road Maintenance and Transportation Organization (Table 1; Fig. 2). Owing to the significant role of climatic parameters in sound propagation [11,24], traffic noise pollution was modeled for two circumstances: one for cold (autumn and winter; from the middle of September to the middle of March) seasons and the other one for warm (spring and summer; from the middle of March to the middle of September) seasons, each with its appropriate set of transportation data. In doing so, two point-based shapefile layer sets (one set for warm and one set for cold seasons) were created within the ESRI's ArcGIS environment (Fig. 3). Each set contains three point-based shapefile layers (each single shapefile is related to each existing Google Earth image from the road between 2010 and 2015). The sound frequency was considered $1000 \mathrm{~Hz}[14,25]$. The sound levels generated from various vehicles were adopted from a study conducted by Madadi et al. (2014) in Isfahan Province, central Iran. They used the $2239 \mathrm{~A}$ sound meter at a distance of 5 meters from the highway in eight different locations along the road to measure sound pressure level of each type of vehicle at a frequency of $1000 \mathrm{~Hz}$.
Table 1 The number, type, and sound level of vehicles passing through the study road

\begin{tabular}{lllcc}
\hline Type of vehicles & Sedan & Pickup & Bus & Truck \\
\hline Mean instantaneous number of vehicles in cold seasons & 89 & 15 & 4 & 17 \\
Mean instantaneous number of vehicles in warm seasons & 77 & 13 & 5 & 15 \\
Mean sound level (dB) in the highway speed limit of 80 km per hour & 73.7 & 77.9 & 76 & 78.1 \\
\hline
\end{tabular}



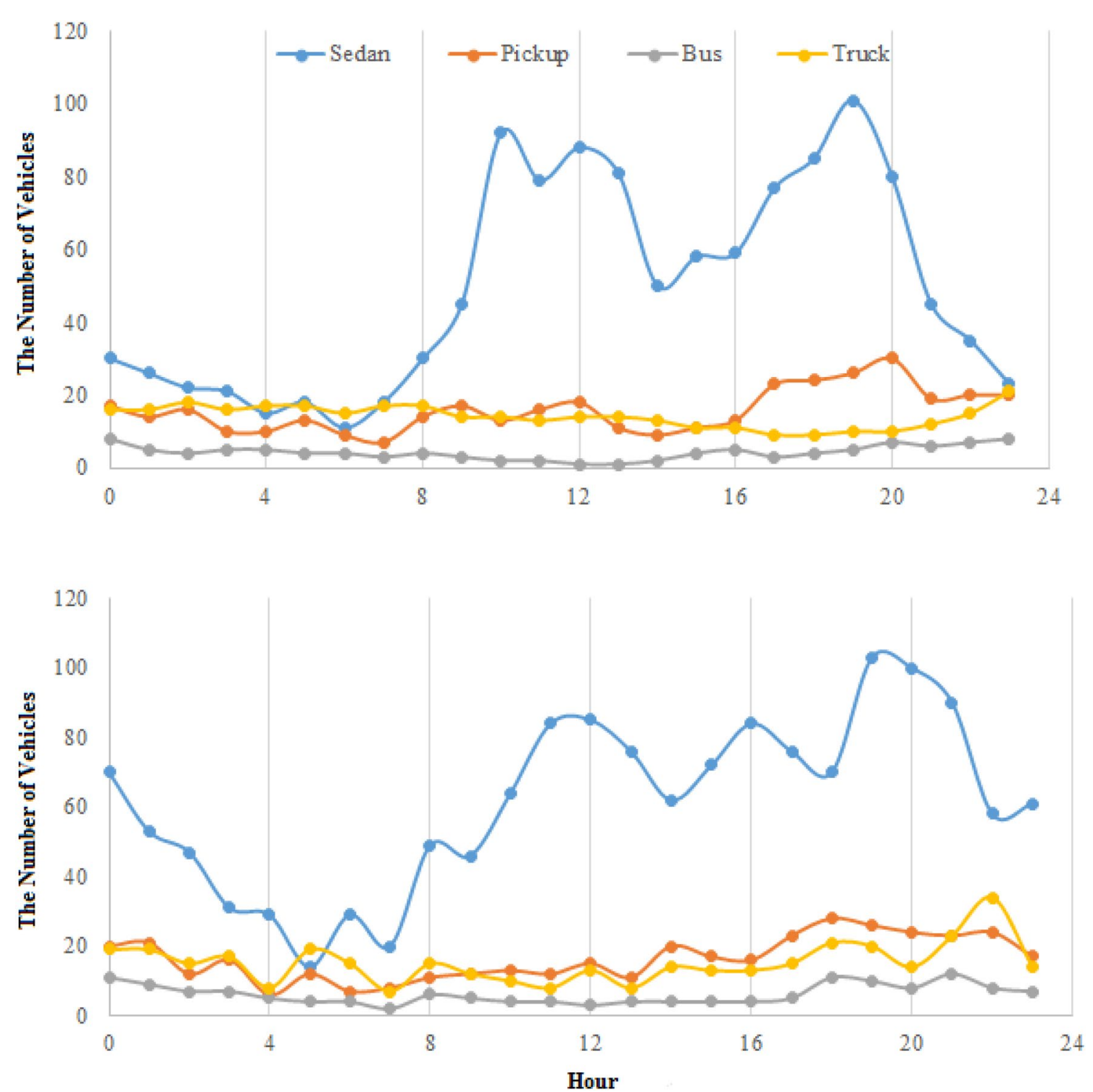

Fig. 2 Mean hourly number of vehicles (2010-2015) in cold (above) and warm (below) seasons

SPreAD-GIS models each point separately and after that calculates the sum of Decibels logarithmically. We ran SPreAD-GIS model for each single point-based shapefile layer and produced three noise propagation maps for each season. Finally, the arithmetic average of these three maps was considered as the final noise propagation map for warm and cold seasons.

\subsection{Physical conditions}

Topography is one of the major contributing factors to sound propagation [12, 24]. In this study, a Digital Elevation Model (DEM) of Mouteh with a pixel size of $30 \mathrm{~m}$ was introduced to the SPreAD-GIS model to identify noise-exposure areas [11]. Land use/land cover, as an underlying determinant factor for background sound level [11], was obtained from the Iranian Department of Environment at the spatial resolution of $30 \mathrm{~m}$. Mean values of daily climate data for a 5-year period (2010-2015) were acquired for the cold and warm seasons from the nearest synoptic station (Golpayegan) to the study area (Table 2).

Wildlife species may exhibit different sensitivity to noise [7]. Drawing from the previous studies in this field, $40 \mathrm{~dB}$ [2] was considered as the threshold at which species react to noise. Based on this and relying on the opinions of a panel of experts, the resulting noise pollution maps were categorized into three noise level classes, as shown in Table 3. 
Fig. 3 A view of instantaneous location of vehicles passing through the study road

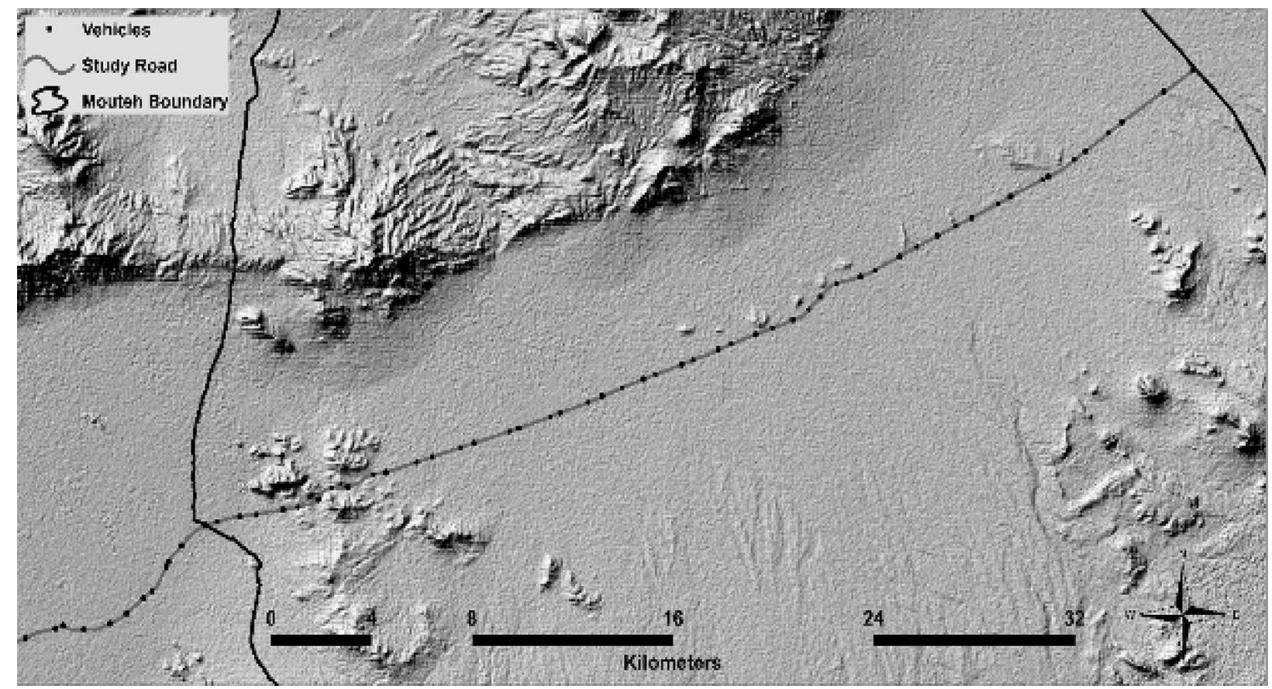

Table 2 The weather data used in this study

\begin{tabular}{lllll}
\hline Period & $\begin{array}{l}\text { Dominant } \\
\text { wind speed } \\
\text { (mph) }\end{array}$ & $\begin{array}{l}\text { Dominant } \\
\text { wind direc- } \\
\text { tion (degree) }\end{array}$ & $\begin{array}{l}\text { Relative } \\
\text { humidity } \\
(\%)\end{array}$ & $\begin{array}{l}\text { Tem- } \\
\text { pera- } \\
\text { ture } \\
(\mathrm{F})\end{array}$ \\
\hline $\begin{array}{l}\text { Warm sea- } \\
\text { sons }\end{array}$ & 8.9 & 305 & 24.8 & 73 \\
Cold seasons & 7.4 & 310 & 49.5 & 42 \\
\hline
\end{tabular}

Table 3 Noise-level classes based on their impacts on wildlife species

\begin{tabular}{llll}
\hline Noise-level classes & Low & Moderate & High \\
\hline$X=$ Noise level $(\mathrm{dB})$ & $20 \geq x$ & $40 \geq x>20$ & $60 \geq x>40$ \\
\hline
\end{tabular}

\subsection{Delineating noise-affected habitats and populations}

Habitat suitability for the Persian gazelle in Mouteh was assessed by calibration of the MaxEnt software with two sets of data: the species' occurrence data from the census conducted by the Iranian Department of Environment in 2015 and environmental layers including slope, geographic aspect, elevation, roughness, vegetation density (mean annual NDVI), and land use (Fig. 4). It is worthy of note that the road layer was intentionally excluded from analysis to look for evidence on the effects of traffic noise propagation on the movement of Persian gazelle populations away from highly suitable noise-affected areas. Relying on the experts' opinions, the resulting habitat suitability map was categorized into four classes: highly suitable (values higher than 0.7), moderately suitable (values between 0.7 and 0.4 ), lowly suitable (values between 0.4 and 0.1), and unsuitable (values lower than 0.1). Finally, the map for noise exposure was overlaid with the habitat suitability map for Persian gazelle to determine to what degree and extent road construction has affected the Persian gazelle's habitats. In addition, we used the population patches data from the census conducted by the Iranian Department of Environment in 2015 (Fig. 5) to identify noise-affected populations of the species.

\section{Results}

Figures 6 and 7 show the classified noise propagation maps for warm and cold seasons of the year, respectively, indicating that around 8308 ha and 6811 ha of the wildlife refuge were influenced by noise pollution during cold seasons and warm seasons of the year, respectively (Fig. 8).

Figure 9 displays the classified habitat suitability map of Persian gazelle in Mouteh. According to the habitat classification scheme, around $26.4 \%(53,461 \mathrm{ha})$ of the total area of the wildlife refuge was recognized as highly suitable, $43.3 \%$ ( $87,776 \mathrm{ha})$ as moderately suitable, $18.6 \%$ ( 37,762 ha) as lowly suitable, and the remaining as unsuitable habitats.

The gazelle populations are likely to receive serious impacts from the road because it exactly runs through the originally most suitable habitats of this species in the central plains of Mouteh. The results showed that 6740 (3.8\%) and $8204.3(4.6 \%)$ ha of potential gazelle habitat were exposed to noise pollution in warm and cold seasons, of which 1395.4 and 1537 ha were classified as high-level noise, 1693 and 1968.6 ha as moderate level noise, 3651.6 and 4698.7 ha as low-level noise, respectively (Fig. 10). 1159.8 and 1522 ha of highly suitable habitats $(5,3461 \mathrm{ha})$ were under noise affection, of which 246 and 283.2 ha were exposed to high-level 
Fig. 4 Environmental layers used for habitat suitability modeling

Fig. 5 The population patches of Persian gazelle in Mouteh wild life refuge

\section{Elevation (m) \\ Low : 1492}
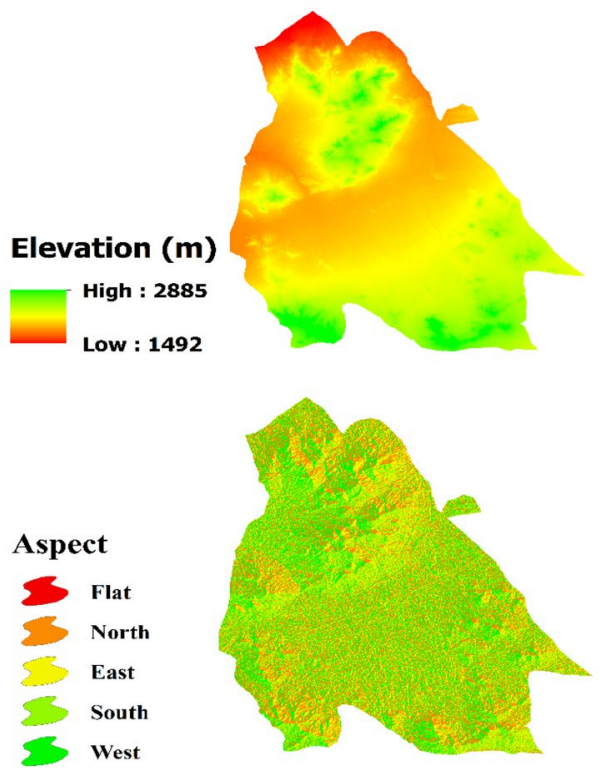

Slope (\%)
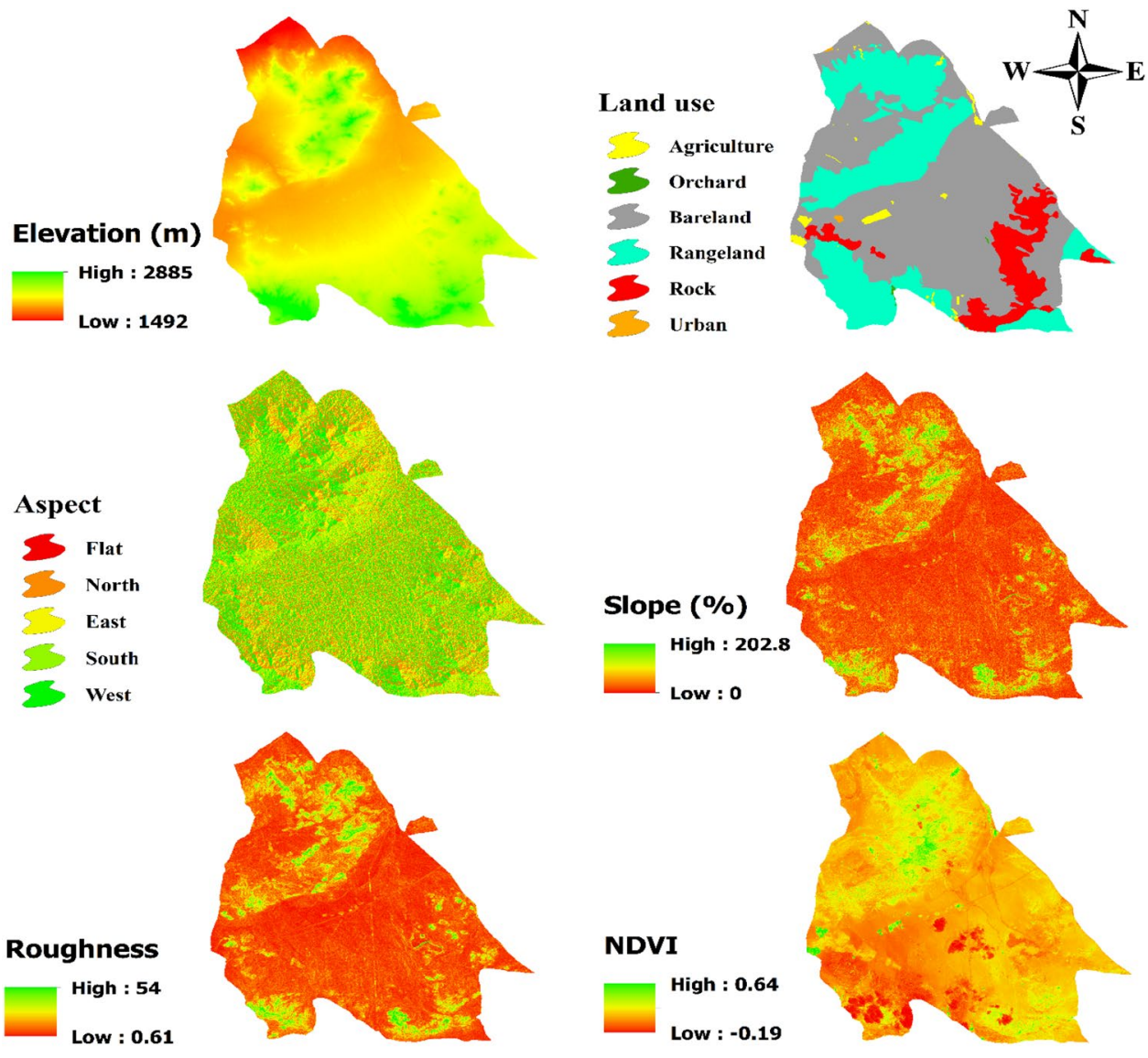

Low : 0

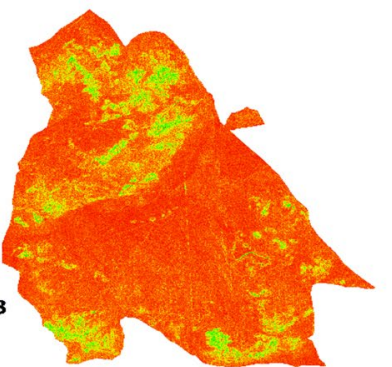

NDVI
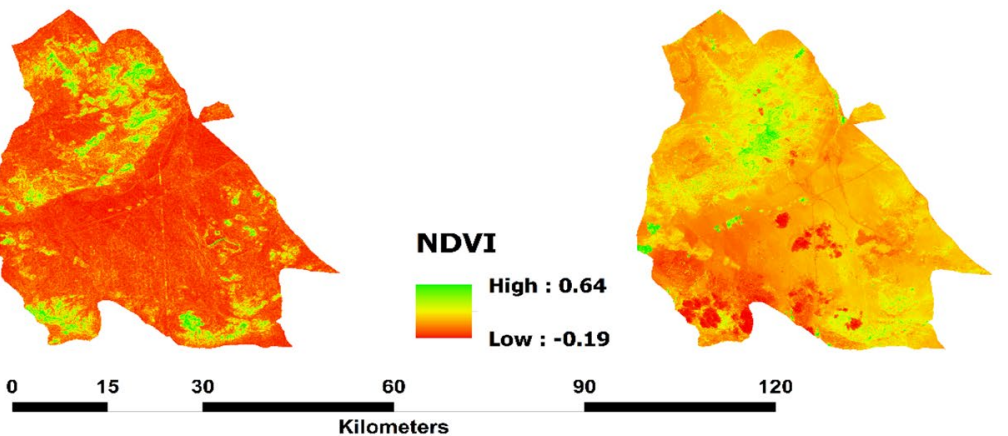

90

120

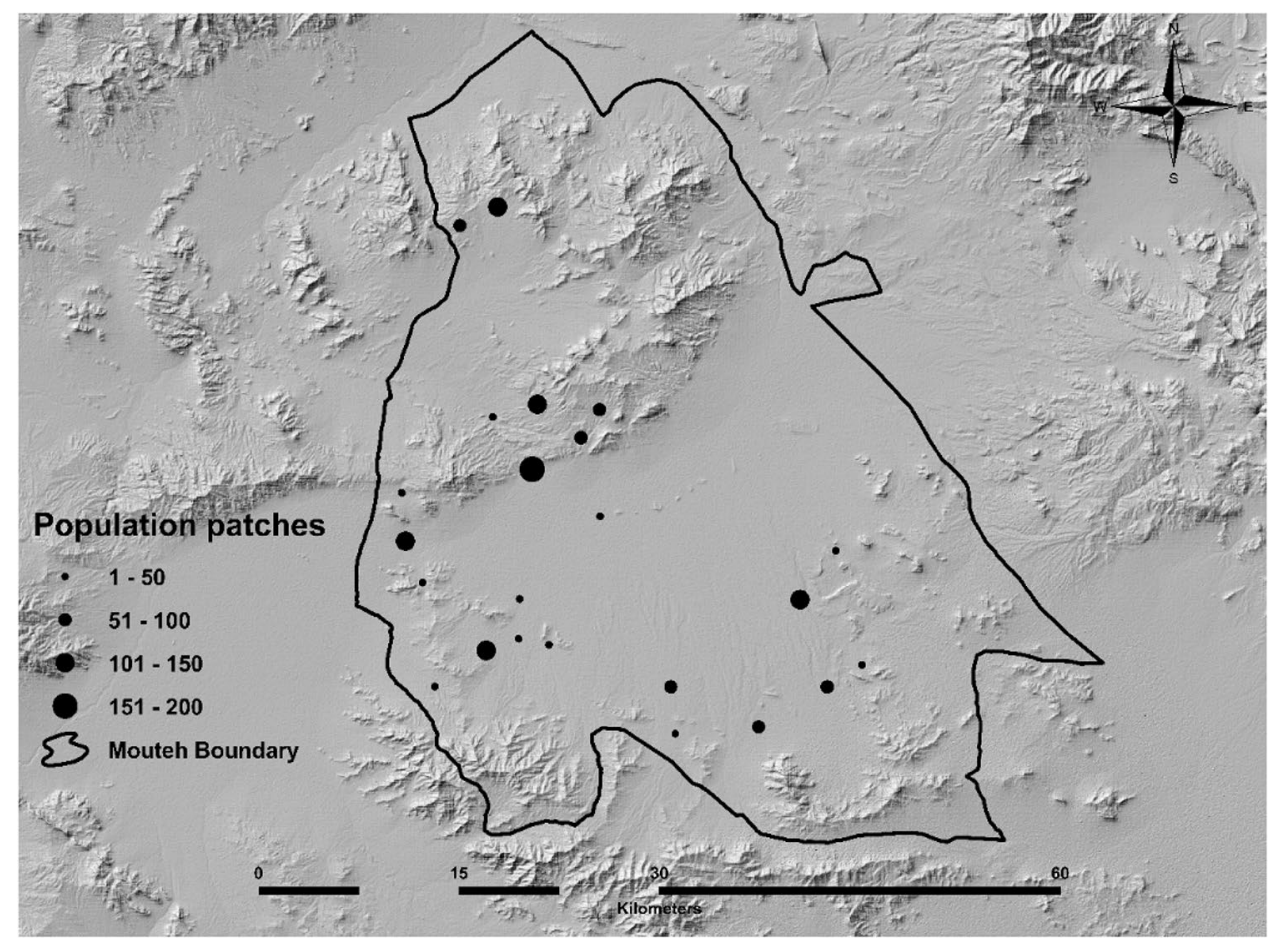


Fig. 6 Road traffic noise-exposure area during warm seasons

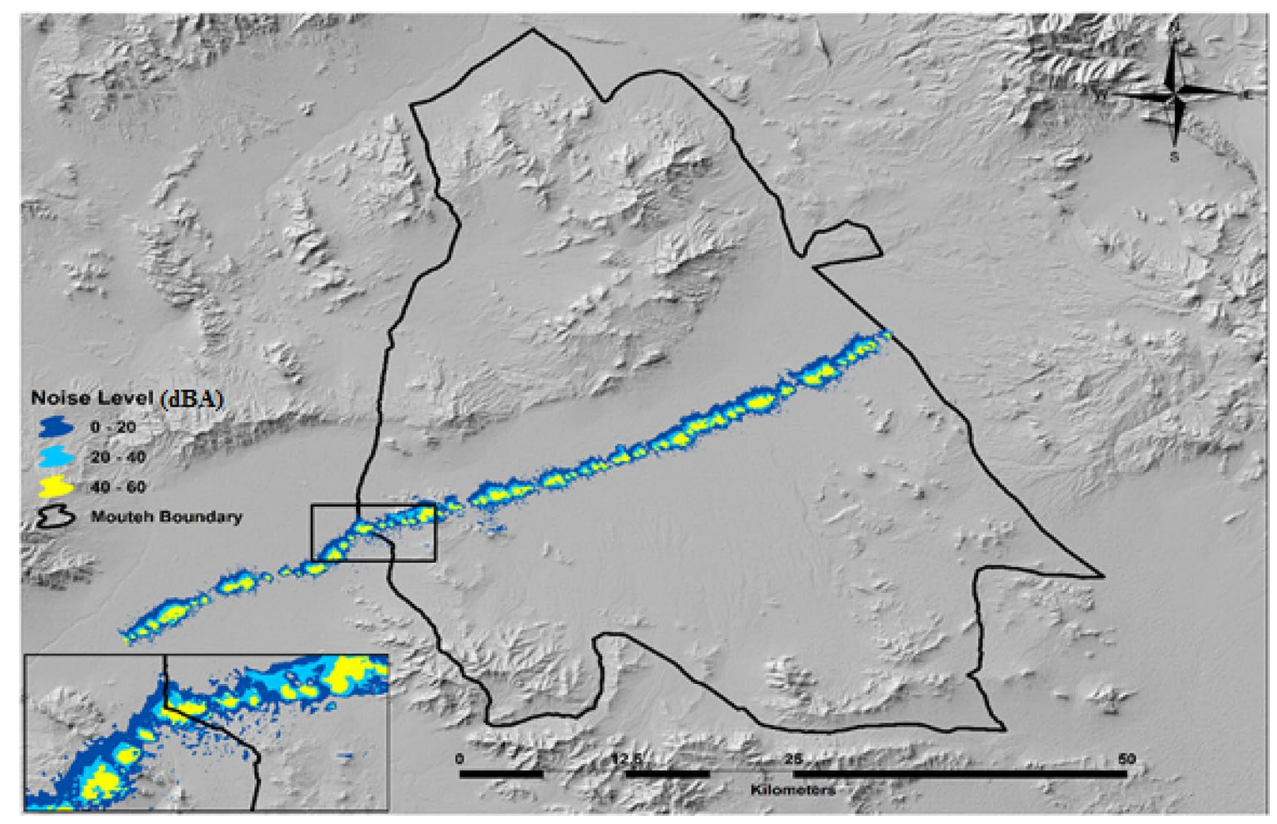

Fig. 7 Road traffic noise-exposure area during cold seasons

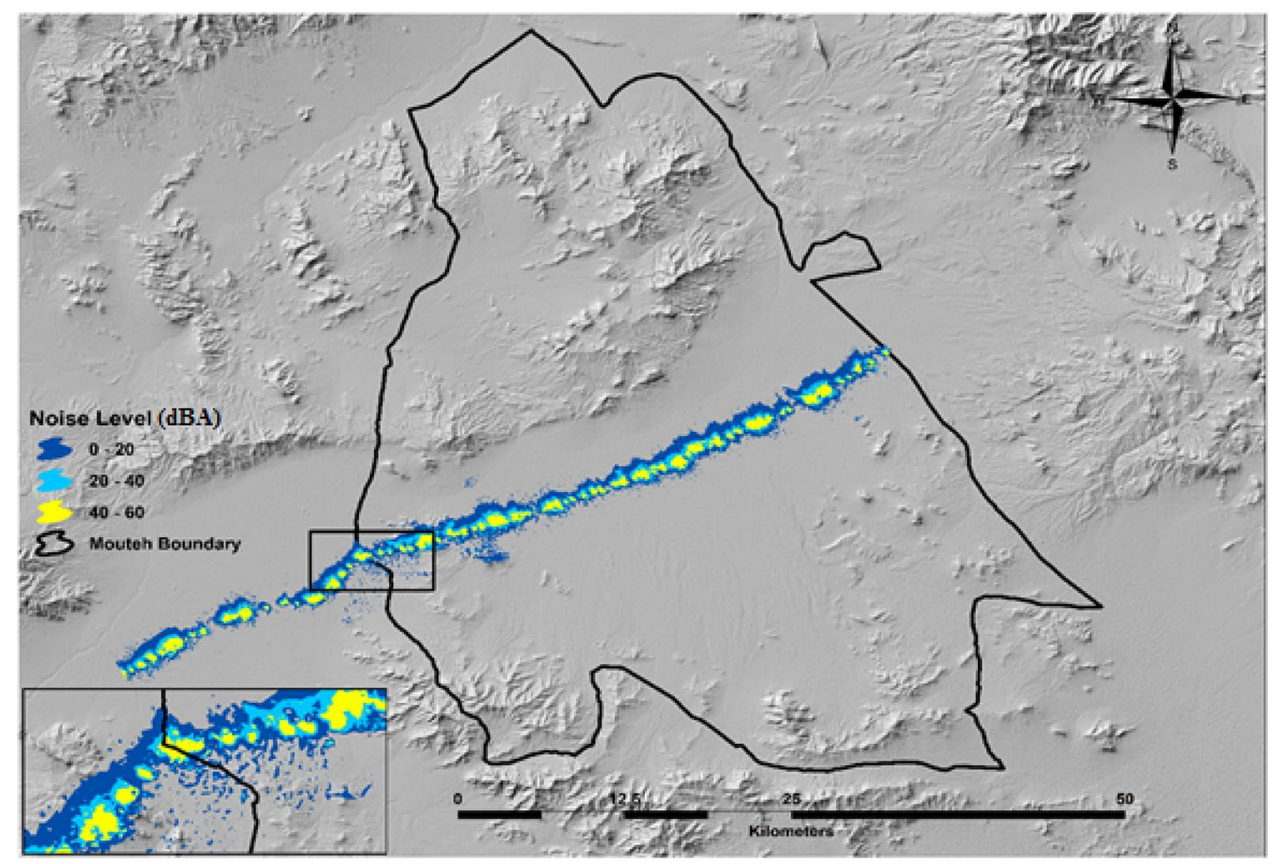

noise, 312.8 and 361.9 ha to moderate level noise, and 601 and 877 ha to low-level noise during warm and cold seasons of the year, respectively (Fig. 10).

\section{Discussion}

Since roads are relatively narrow linear structures, direct destruction of wildlife habitat is limited. But indirectly, roads contribute to numerous adverse impacts on wildlife beyond their physical extent. Traffic noise may affect wildlife habitats and their constituent species by generating noise-exposure areas extending from a few meters to a several kilometers. Although the majority of studies on the ecological impacts of roads and other linear infrastructures were based just on land-take, a few studies have tried to identify road-induced noise-exposure zones [26-28]. The results of this study showed that traffic noise pollution influenced as much as 6811 ha of the road's surrounding area during the warm seasons and 8308 ha during 
Fig. 8 Various levels and total (ha) of noise affectation areas during warm and cold seasons

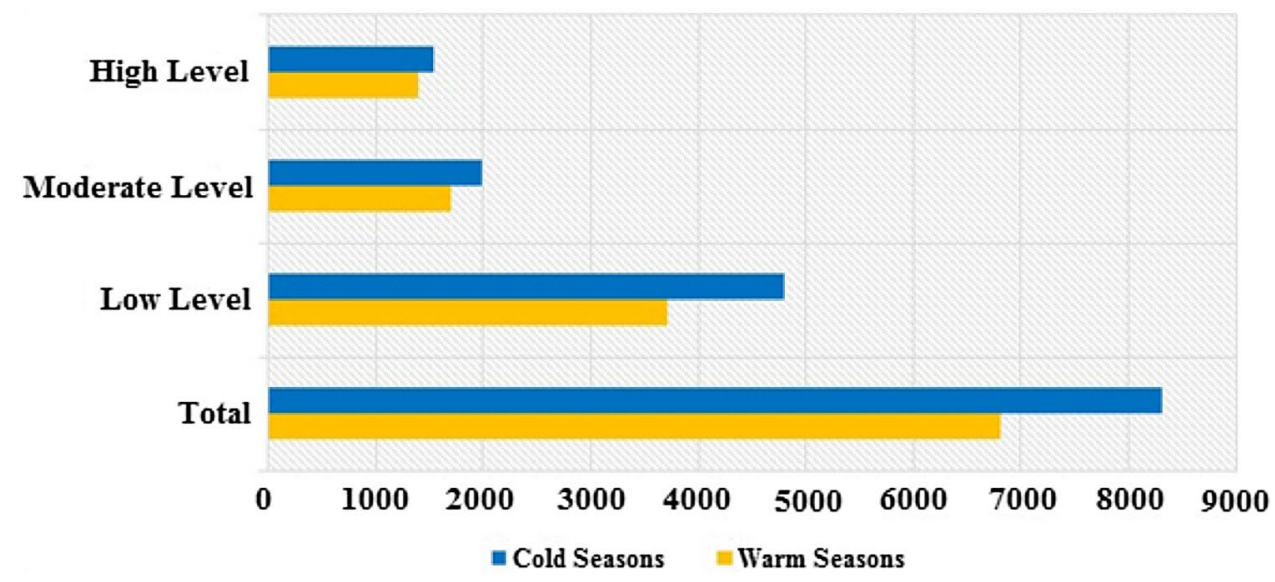

Fig. 9 The classified habitat suitability map of Persian gazelle in Mouteh

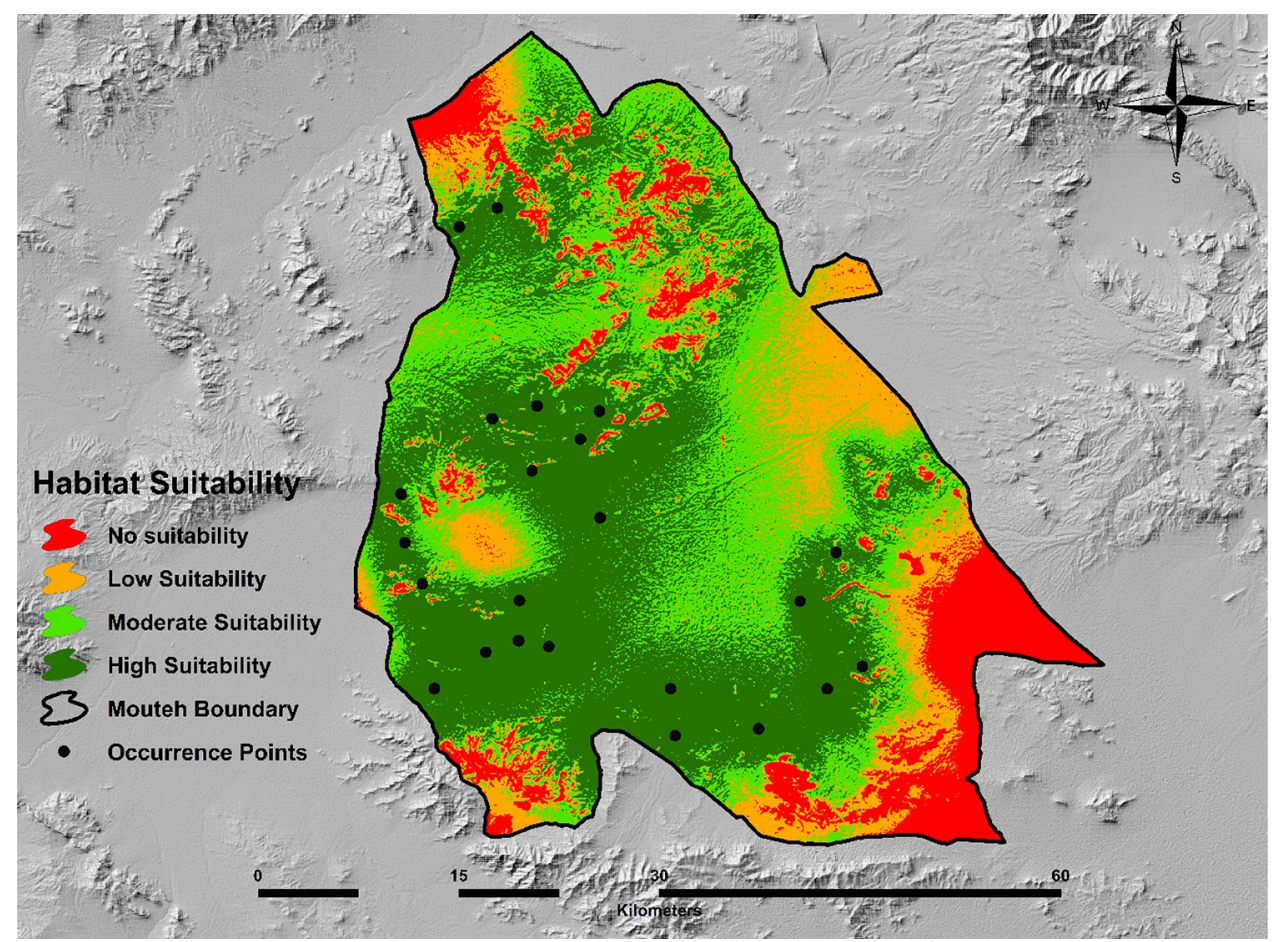

the cold seasons of the year; even so, the physical extent of the road itself accounted for a direct loss of just about 132 ha. Such a notable difference between the physical surface of the road and the generated noise-exposure areas highlights the importance of integrating the effects of traffic noise pollution into road environmental impact assessments and the management of wildlife populations. It is also worth noting that in this study, we used mean instantaneous number of vehicles in cold and warm seasons while traffic levels vary within a 24-hour period (see Fig. 2) and such variation could affect the extent and degree of the generated noise-exposure areas.

Habitat less used or even abandoned because of noise may be used as an indicator for "functional habitat loss." It may become important in areas where the severity of noise exceeds the species' tolerance limits [10, 29]. Other studies on ecological impacts of noise pollution have focused on a different noise-level threshold depending on the target species, ranging from $42 \mathrm{~dB}$ [27] to $50 \mathrm{~dB}$ [26]. For this study, however, we used the general noise threshold of $40 \mathrm{~dB}$ proposed for wildlife [2], because field surveys indicated that most individuals of Persian gazelle avoid high-level noise areas (noise level $>40 \mathrm{~dB}$ ), indicating that high-level noise-affected habitats of Persian gazelle have been functionally lost.

Roads are also known as a barrier for wildlife movement. In fact, roads based on their type, width, and traffic volume may result in a fragmented wildlife habitat, disconnected wildlife and isolated populations [10,30,31]. The width of roads is one of the most affecting factors on the number 


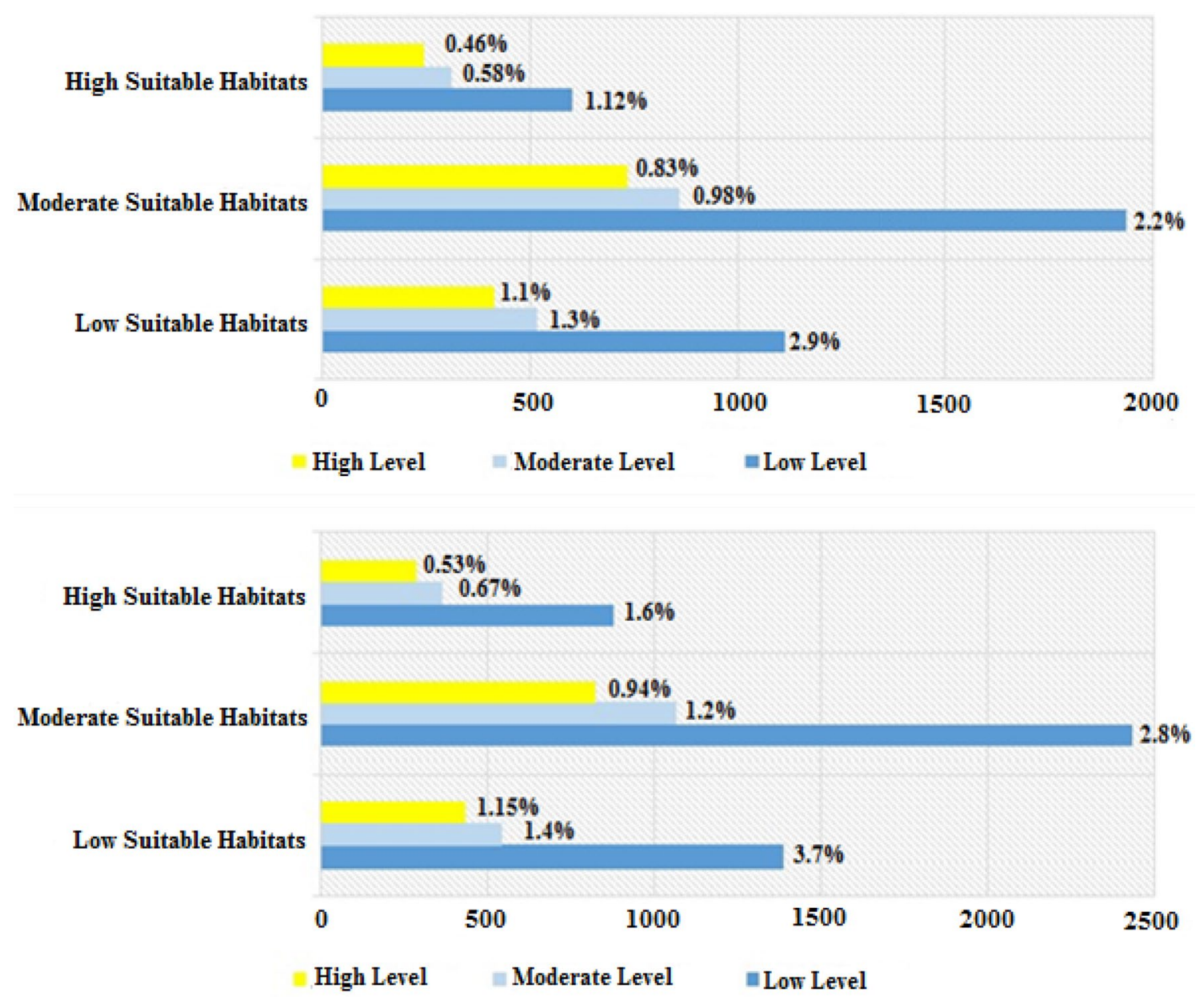

Fig. 10 Area (ha) of noise-affected habitats during warm (above) and cold (below) seasons

of wildlife passing over the road [31]. Although some of the studies on the fragmentation due to roads and other linear infrastructures were based on land-take, some other studies focused on the road effect zone caused by noise pollution $[7,10,19,27]$. The study road divides the wildlife refuge into two disconnected parts (northern and southern) and consequently disconnects the populations of Persian gazelle. Given that high-level noise-affected habitats of Persian gazelle have been abandoned by species and functionally lost, we can consider the width of the road equivalent to this area. In this case, the width of the road increases from an average of 30-600 m and consequently the movement of Persian gazelles becomes more difficult.

Individuals staying in noise-affected habitats may not be entirely noise tolerant and may experience a variety of adverse ecological consequences related to mating behavior and reproductive success, genetic diversity, stress, communication, and temporal activity patterns which may eventually affect their fitness [2, 32]. For instance, noise exposure was found to be relatively unimportant for habitat selection in oven bird (Seiurus aurocapilla) while mate attraction was found rather unsuccessful in noisy territories [8, 33, 34]. Moreover, pairing success rate by reed buntings (Emberiza schoeniclus) showed a decreasing trend with noise increasing [35]. Several other potential costs may be associated with exposure to noise but need further investigation. In this study, also few individuals were found in moderate and low-level noise areas (see Figs. 5, 6, 7). Our findings indicate that habitat occupancy is a necessary, but not sufficient, determinant to investigating the effect of noise on species and should, therefore, be studied in combination with other fitness-relevant factors such as mating success, number and survival of offspring, and physiological stress to effectively plan conservation of sensitive wildlife populations. However, considering taking the whole range of potential impacts may be constrained by limited funding and logistics. Such circumstances may even call for procedures that incorporate a feasible number of metrics sufficient to describe how noise influences species.

The identification of the affected habitats and populations through modeling can be an appropriate and 
cost-effective means to determine the primary species response to traffic noise and minimize its adverse impacts for sustainably managing wildlife populations. However, modeling constraints and uncertainties should also be considered. In this study, we were confronted with limitations such as limited occurrence points (only 23) for Persian gazelle habitat suitability modeling, the lack of knowledge on acoustic behavior of the target species, and using a static model (as the only free model for noise propagation modeling in natural areas) for mobile sources. Using a single frequency $(1000 \mathrm{~Hz})$ due to lack of data availability also was one of the most important limitations in this study because it is expected that lower frequencies are audible to ungulates and travel further across landscape $[36,37]$.

\section{Conclusion}

As a spatially extensive pollutant, evidence suggests that noise impose harmful impacts on wildlife species. In this study, we used the SPreAD-GIS noise propagation model to estimate functional habitat loss and identify noiseexposure habitats. We found that the noise propagation modeling can lead to better formulation of conservation plans by providing valuable insights into the ecological impacts of noise across natural and protected areas. Noise propagation modeling can therefore improve ecological impact assessment of roads and facilitate successful implementation of conservation plans.

Acknowledgements We are grateful to the Iranian Department of Environment for providing us with data and their valuable companionship in this study.

\section{Compliance with ethical standards}

Conflict of interest On behalf of all the authors, the corresponding author declares that there is no conflict of interest in this research article.

\section{References}

1. Dumyahn SL, Pijanowski BC (2011) Soundscape conservation. Landsc Ecol 26(9):13-27

2. Shannon G, McKenna MF, Angeloni LM, Crooks KR, Fristrup KM et al (2016) A synthesis of two decades of research documenting the effects of noise on wildlife. Biol Rev 91(4):982-1005

3. Francis CD, Kleist NJ, Ortega CP, Cruz A (2012) Noise pollution alters ecological services: enhanced pollination and disrupted seed dispersal. Proc R Soc B 279(1739):2727-2735

4. Slabbekoorn $\mathrm{H}$, Bouton $\mathrm{N}$, van Opzeeland I, Coers A, ten Cate $\mathrm{C}$, Popper AN (2010) A noisy spring: the impact of globally rising underwater sound levels on fish. Trends Ecol Evol 25(7):419-427
5. Barber JR, Crooks KR, Fristrup KM (2010) The costs of chronic noise exposure for terrestrial organisms. Trends Ecol Evol 25(3):180-189

6. Francis CD, Barber JR (2013) A framework for understanding noise impacts on wildlife: an urgent conservation priority. Front Ecol Environ 11(6):305-313. https://doi.org/10.1890/120183

7. Jaeger JAG, Bowman J, Brennan J, Fahrig L et al (2005) Predicting when animal populations are at risk from roads: an interactive model of road avoidance behavior. Ecol Modell 185:329-348

8. Bayne EM, Habib L, Boutin S (2008) Impacts of chronic anthropogenic noise from energy-sector activity on abundance of songbirds in the boreal forest. Conserv Biol 22(5):1186-1193

9. Eigenbrod F, Hecnar SJ, Fahrig $L$ (2008) The relative effects of road traffic and forest cover on anuran populations. Biol Conserv 141(1):35-46

10. Madadi H, Moradi H, Soffianian A, Salmanmahiny A, Senn J, Geneletti D (2017) Degradation of natural habitats by roads: comparing land-take and noise effect zone. Environ Impact Assess Rev 65:147-155. https://doi.org/10.1016/j.eiar.2017.05.003

11. Reed SE, Boggs JL, Mann JP (2012) A GIS tool for modeling anthropogenic noise propagation in natural ecosystems. Environ Modell Softw 37:1-5. https://doi.org/10.1016/j.envso ft.2012.04.012

12. Keyel AC, Reed SE, McKenna MF, Wittemyer G (2017) Modeling anthropogenic noise propagation using the Sound Mapping Tools ArcGIS toolbox. Environ Modell Softw 97:56-60. https:// doi.org/10.1016/j.envsoft.2017.07.008

13. Pijanowski BC, Villanueva-Rivera LJ, Dumyahn SL et al (2011) Soundscape ecology: the science of sound in the landscape. BioScience 61(3):203-216

14. Barber JR, Burdett $C L$, Reed $S E$, Warner $K A$, Formichella $C$ et al (2011) Anthropogenic noise exposure in protected natural areas: estimating the scale of ecological consequences. Landsc Ecol 26(9):12-18. https://doi.org/10.1007/s10980-011-9646-7

15. Grade AM, Sieving KE (2016) When the birds go unheard: highway noise disrupts information transfer between bird species. Biol Lett 12:20160113

16. Dulac J (2013) Global land transport infrastructure requirements. Paris Int Energy Agency 20:2014

17. Laurance WF, Clements GR, Sloan S et al (2014) A global strategy for road building. Nature 513:22

18. Geneletti $D$ (2006) Some common shortcomings in the treatment of impacts of linear infrastructures on natural habitat. Environ Impact Assess Rev 26(3):257-267

19. Forman RTT, Deblinger RD (2000) The ecological road-effect zone of a Massachusetts (USA) suburban highway. Conserv Biol 14(1):36-46

20. Shanley CS, Pyare S (2011) Evaluating the road-effect zone on wildlife distribution in a rural landscape. Ecosphere 2(2):1-16

21. Mohammed OB, Davies AJ, Daszak P, Hussein HS (2000) Sarcocystis infections in gazelles at the king khalid wildlife research centre, Saudi Arabia. Vet Rec 146:218

22. Kingswood SC, Blank DA (1996) Gazella subgutturosa. Mamm. Species 518:1-10. https://doi.org/10.2307/3504241

23. Nowzari H, Hemami M, Behrouzi Rad B (2007) Habitat use by Persian Gazelle (Gazella subgutturosa) in Bamoo National Park during Autumn and Winter. Acta Zool Mex 23(1):109-121

24. Heimann D (2013) Wide-area assessment of topographical and meteorological effects on sound propagation by timedomain modeling. J Acoust Soc Am 133(5):419-425. https:// doi.org/10.1121/1.4802185

25. Madadi H, Moradi H, Fakheran S, Jokar M, Makki T (2014) Modeling the propagation of noise pollution from Isfahan's West Ringway in Ghamishloo wildlife refuge using SPreAD-GIS TT. IJAE 3(9):43-56. Retrieved from http://ijae.iut.ac.ir/article-1-565-fa. html 
26. Nega T, Yaffe N, Stewart N, Fu WH (2013) The impact of road traffic noise on urban protected areas: a landscape modeling approach. Transp Res D 23:98-104

27. Reijnen R, Foppen $R$ (2006) Impact of road traffic on breeding bird populations. The ecology of transportation: managing mobility for the environment. Springer, Berlin, pp 255-274

28. Helldin JO, Collinder P, Bengtsson D, Karlberg Å, Askling J (2013) Assessment of traffic noise impact in important bird sites in Sweden-a practical method for the regional scale. Oecol Austr 17(1):48-62

29. Bashari $\mathrm{H}$, Hemami MR (2013) A predictive diagnostic model for wild sheep (Ovis orientalis) habitat suitability in Iran. J Nat Conserv 21(5):319-325

30. Shi H, Shi T, Yang Z, Wang Z, Han F, Wang C (2018) Effect of roads on ecological corridors used for wildlife movement in a natural heritage site. Sustainability 10(8):2725

31. Mader HJ (1984) Animal habitat isolation by roads and agricultural fields. Biol Conserv 29(1):81-96. https://doi. org/10.1016/0006-3207(84)90015-6

32. Francis CD, Barber JR (2013) A framework for understanding noise impacts on wildlife: an urgent conservation priority. Front Ecol Environ 11(6):305-313
33. Habib L, Bayne EM, Boutin S (2007) Chronic industrial noise affects pairing success and age structure of ovenbirds Seiurus aurocapilla. J Appl Ecol 44(1):176-184

34. Goodwin SE, Shriver WG (2011) Effects of traffic noise on occupancy patterns of forest birds. Conserv Biol 25(2):406-411

35. Gross K, Pasinelli G, Kunc HP (2010) Behavioral plasticity allows short-term adjustment to a novel environment. Am Nat 176(4):456-464

36. Hefner JH, Hefner EH (2010) The behavioral audiogram of whitetail deer (Odocoileus virginianus). J Acoust Soc Am 127(3):111-114

37. Flydal K, Hermansen A, Enger PS, Reimers E (2001) Hearing in reindeer (Rangifer tarandus). J Comp Phsiol 187(4):265-269

Publisher's Note Springer Nature remains neutral with regard to jurisdictional claims in published maps and institutional affiliations. 